\title{
Barley grass extract causes apoptosis of cancer cells by increasing intracellular reactive oxygen species production
}

\author{
SANG MI WOO ${ }^{*}$, SANG-CHUL KWON ${ }^{2 *}$, SEONG GYU KO ${ }^{1}$ and SUNG-GOOK CHO ${ }^{3}$ \\ ${ }^{1}$ Department of Science in Korean Medicine, Graduate School of Kyung Hee University, \\ Seoul 130-701; Departments of ${ }^{2}$ Food Technology and ${ }^{3}$ Biotechnology, Korea National \\ University of Transportation, Jeungpyeong, Chungbuk 368-701, Republic of Korea
}

Received November 11, 2016; Accepted January 10, 2017

DOI: $10.3892 /$ br.2017.897

\begin{abstract}
Cancer remains a leading cause of mortality worldwide, therefore food products are being investigated for potential prevention or treatment strategies. The ingredient, barley grass extract (Hordeum vulgare L.; Bex) is used to prevent or ameliorate various types of disease. In cancer, Bex has been revealed to inhibit tumor growth. However, its effect on cancer cells is yet to be clearly defined. In the present study, the effect of Bex on cancer cell growth was investigated. Bex inhibited the viabilities of breast and prostate cancer cells according to the results of MTT assays. Accordingly, Bex caused apoptosis, which was confirmed by Annexin V staining and western blot analysis for poly (ADP-ribose) polymerase and caspases. Furthermore, Bex increased the intracellular levels of reactive oxygen species (ROS), and $\mathrm{N}$-acetyl-L-cystein blocked Bex-induced apoptosis. Therefore, the study demonstrated that Bex causes apoptosis of breast and prostate cancer cells by increasing intracellular ROS levels.
\end{abstract}

\section{Introduction}

Cancer is one of the leading causes of mortality worldwide $(1,2)$. Despite numerous cancer studies and the development of various anti-cancer therapeutic agents, cancer remains dangerous. Anti-cancer therapeutic agents are chemically or biologically produced, and their effects are well defined (3-7). However, treatments continue to be associated with adverse effects and the majority of patients have an aversion to them (8).

Herbal products have long been used to prevent or treat diseases, including cancer (9-12). Furthermore, certain anti-cancer therapeutic agents that are chemically produced originate from herbal products and their chemical

Correspondence to: Professor Sung-Gook Cho, Department of Biotechnology, Korea National University of Transportation, 61 University Road, Jeungpyeong, Chungbuk 368-701, Republic of Korea

E-mail: chosg@ut.ac.kr

*Contributed equally

Key words: barley grass extract, cancer, reactive oxygen species characteristics are modified (7,12-14). Typically, patients prefer to take herbal products (15-18); herbal products have historically been used as traditional medicines, such as traditional Chinese and Korean medicines, Kampo medicines and Ayurvedic medicine $(13,14,19)$. Certain herbal products were demonstrated to treat cancer and/or reduce the side effects of cancer treatment $(13,15-17,19-21)$. Therefore, herbal products are considered to be promising for cancer prevention and treatment.

Barley grass extract (Hordeum vulgare L.; Bex) has long been used as a food product. Its biological effects have also been addressed by various in vitro and in vivo studies, although evidence there is limited evidence of the efficacy of Bex against specific conditions (22). The effect of Bex on the immune system was revealed in in vitro and in vivo experimental sets (23-25). Accordingly, Bex inhibited atopic dermatitis in NC/Nga mice by altering the expression levels of cytokines (26). Similarly, Bex repressed lipopolysaccharide-induced inflammation (27). Furthermore, its effect in type 2 diabetes was revealed in a genetically engineered mouse model and patients $(28,29)$. Therefore, the effects of Bex on particular diseases have been demonstrated at least in experimental systems. A previous study revealed that Bex caused apoptosis of leukemia and lymphoma cell lines (30); however, its effect in cancer remains unclear.

The present study examined the effect of Bex in different cancer cell lines, including breast cancer MDA-MB-231 cells and prostate cancer DU145 cells. Bex induced apoptotic cell death in MDA-MB-231 and DU145 cells. Furthermore, its effect resulted from an increased intracellular reactive oxygen species (ROS) level. Thus, the current study suggests that Bex may be useful for treating cancer, particularly breast and prostate cancer.

\section{Materials and methods}

Cell culture and herbal extract. MDA-MB-231 and DU-145 cells (American Type Culture Collection, Manassas, VA, USA) were cultured in Dulbecco's modified Eagle's medium with $10 \%$ fetal bovine serum and $1 \%$ penicillin-streptomycin (all Gibco; Thermo Fisher Scientific, Inc., Waltham, MA, USA). Barley grass extract (Bex) was obtained from Chungbuk Agricultural Cooperation (Jecheon, South Korea). Bex was 
MDA-MB-231

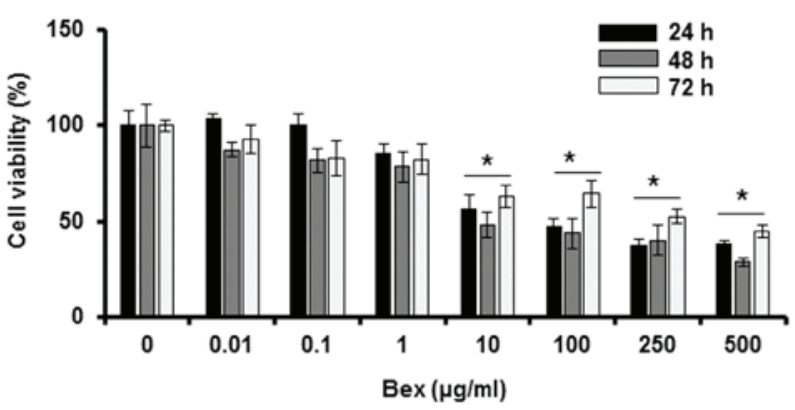

DU 145

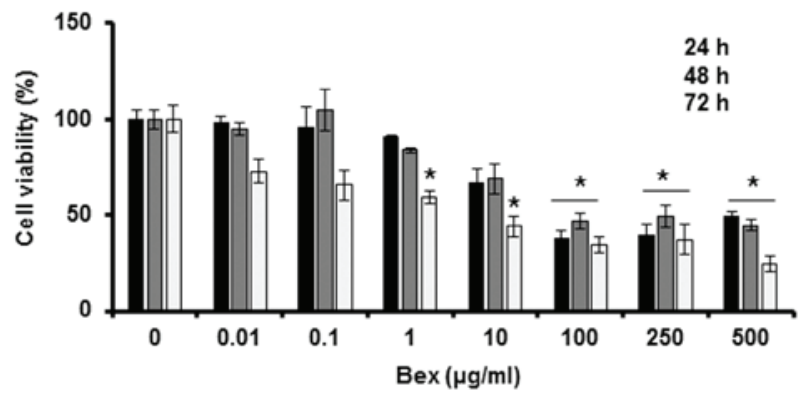

Figure 1. Bex reduces MDA-MB-231 and DU-145 cell viabilities. Cells were treated with different concentrations $(0,0.01,0.1,1,10,100,250$ and $500 \mu \mathrm{g} / \mathrm{ml})$ of Bex for $72 \mathrm{~h}$. Cell viabilities were measured at 24,48 and $72 \mathrm{~h}$. ${ }^{*} \mathrm{P}<0.05 \mathrm{vs} .0 \mu \mathrm{g} / \mathrm{ml}$. Bex, barley grass extract.

A
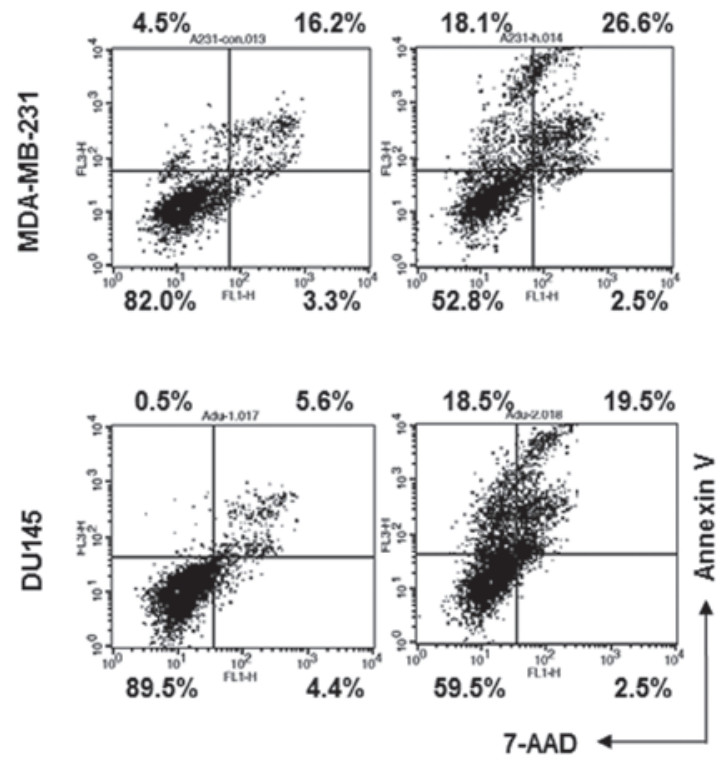

B

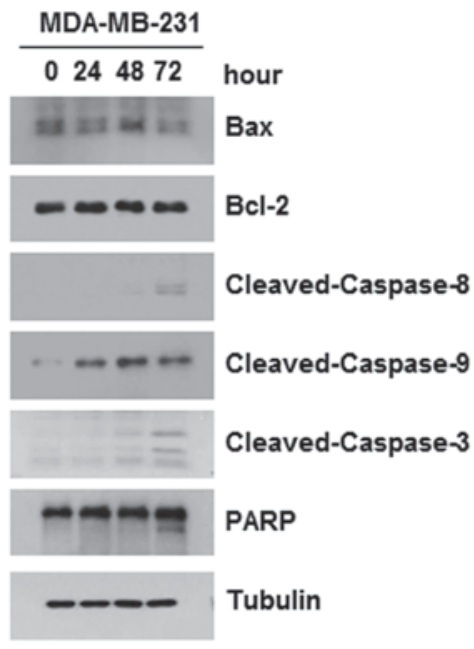

Figure 2. Bex induces apoptotic cell death. (A) Cells were treated with $100 \mu \mathrm{g} / \mathrm{ml} \mathrm{Bex} \mathrm{for} 24 \mathrm{~h}$ and subjected to Annexin V-fluorescein isothiocyanate and 7-AAD staining. (B) MDA-MB-231 cells were treated with $100 \mu \mathrm{g} / \mathrm{ml}$ Bex for $24 \mathrm{~h}$ and subjected to western blot analysis. Bex, barley grass extract; 7-AAD, 7-aminoactinomycin D; Bax, BCL2 associated X, apoptosis regulator; Bcl-2, B-cell lymphoma 2; PARP, poly (ADP-ribose) polymerase.

solubilized in water containing $0.01 \%$ dimethyl sulfoxide (DMSO). Therefore, all control groups in the experiment were treated with $0.01 \%$ DMSO.

Cell viability assay. Cell viability was examined using an EZ-CYTOX cell viability/cytotoxicity assay kit (cat. no. EZ-000, Daeil Lab Service, Seoul, South Korea) according to the manufacturer's instructions. Briefly, 100,000 cells per well were cultured in 96-well plates and treated with different doses $(0,0.01,0.1,1,10,100,250$ and $500 \mu \mathrm{g} / \mathrm{ml})$ of Bex for $72 \mathrm{~h}$. Cell viability at 24,48 and $72 \mathrm{~h}$ was measured using a microplate reader at a wavelength of $450 \mathrm{~nm}$. Experiments were performed in triplicate and repeated three times independently.

Apoptosis assay. Cells $\left(3 \times 10^{6}\right)$ were treated with different concentrations $(0,0.01,0.1,1,10,100,250$ and $500 \mu \mathrm{g} / \mathrm{ml})$ of Bex for $24 \mathrm{~h}$ and stained with Annexin V-fluorescein isothio cyanate (FITC) and 7-aminoactinomycin D (7-AAD). Apoptotic cell death was determined using BD FACSCalibur flow cyto metry with BD MultiSET software (BD Biosciences, San Jose,
CA, USA). For western blot analysis, $1 \times 10^{6}$ cells were treated with $100 \mu \mathrm{g} / \mathrm{ml}$ Bex for $24 \mathrm{~h}$ and lysed with RIPA buffer. Protein $(30 \mu \mathrm{g})$ was loaded onto SDS-PAGE and transferred to the membrane. After blocking with 5\% milk, the membrane was incubated with an appropriate primary antibody for $1 \mathrm{~h}$ at room temperature. Anti-poly(ADP-ribose) polymerases (PARP) (cat. no. 9542), anti-cleaved caspase 8 (cat. no. 9496), anti-cleaved caspase 9 (cat. no. 7237), anti-cleaved caspase-3 (cat. no. 9664) and anti- $\beta$-tubulin (cat. no. 2146) antibodies were obtained from Cell Signaling Technology, Inc. (Danvers, MA, USA).

Intracellular ROS detection assay. ROS levels were measured using $10 \mu \mathrm{M}$ 2',7'-dichlorofluorescin diacetate (H2DCF-DA; Molecular Probes; Thermo Fisher Scientific, Inc., Waltham, MA, USA). Cells $\left(1 \times 10^{6}\right)$ were treated with $100 \mu \mathrm{g} / \mathrm{ml}$ Bex for $5 \mathrm{~min}$ and treated with H2DCF-DA for a further $24 \mathrm{~h}$. The flow cytometry experiments were conducted in triplicate and repeated three times independently. Sigma-Aldrich $N$-acetyl-L-cystein (NAC; Merck KGaA, Darmstadt, Germany) 
MDA-MB-231
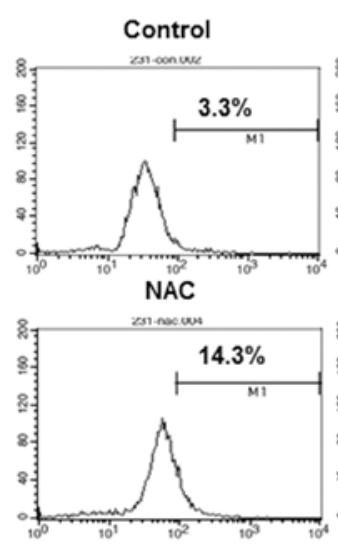
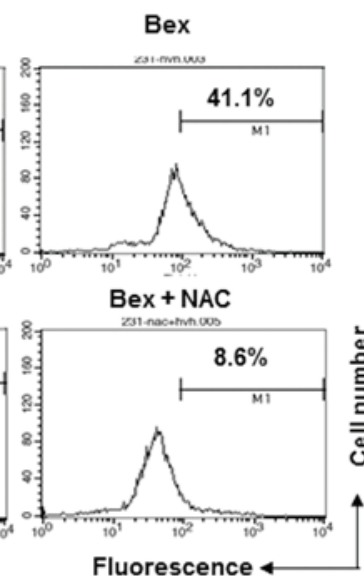

DU145

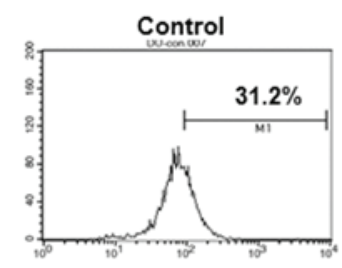

NAC

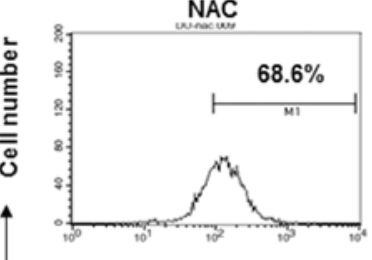

Figure 3. Bex increases intracellular reactive oxygen species level. MDA-MB-231 and DU-145 cells were pretreated with $10 \mathrm{mM}$ NAC for $1 \mathrm{~h}$ before being treated with $100 \mu \mathrm{g} / \mathrm{ml}$ Bex for $24 \mathrm{~h}$. Bex, barley grass extract; NAC, N-acetyl-L-cystein.

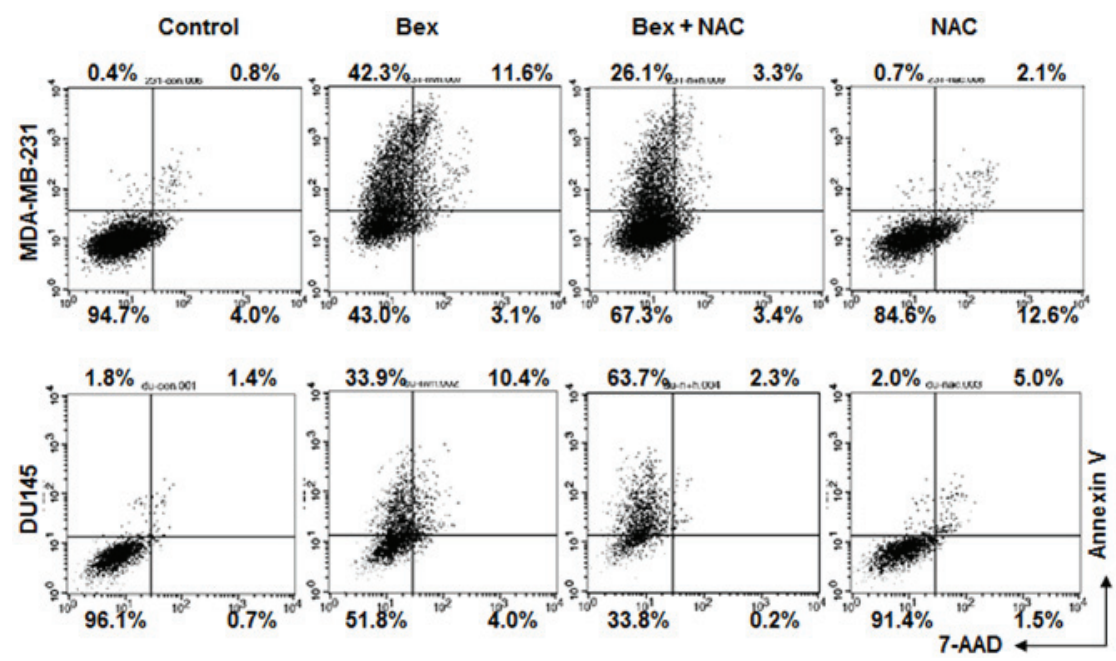

Figure 4. Bex-induced apoptosis requires intracellular reactive oxygen species production. Cells were treated with Bex for $24 \mathrm{~h}$ with or without NAC, and then subjected to Annexin V-fluorescein isothiocyanate and 7-AAD staining. Bex, barley grass extract; NAC, $N$-acetyl-L-cystein; 7-AAD, 7-aminoactinomycin D.

at $10 \mathrm{mM}$ was used to inhibit ROS induction. Cells $\left(1 \times 10^{6}\right)$ were pretreated with $10 \mathrm{mM}$ NAC for $1 \mathrm{~h}$ before being treated with $100 \mu \mathrm{g} / \mathrm{ml}$ Bex for $24 \mathrm{~h}$.

Statistical analysis. All experiments were performed in triplicate and repeated three times independently. Statistical significance was evaluated using Student's t-test and analysis was conducted using SPSS version 24.0 software (IBM Corp., Armonk, NY, USA). P $<0.05$ was considered to indicate a statistically significant difference.

\section{Results}

Bex inhibits cancer cell viability. To examine the effect of Bex on cancer cell viability, MDA-MB-231 breast cancer cells and DU-145 prostate cancer cells were treated with different concentrations $(0,0.01,0.1,1,10,100,250$ and $500 \mu \mathrm{g} / \mathrm{ml})$ of Bex for 24, 48 and $72 \mathrm{~h}$. Bex reduced the viability of those cancer cells in a dose-dependent manner (Fig. 1). Thus, the MTT assay data indicates that Bex inhibits cancer cell viability.
Bex causes apoptosis of cancer cells. Annexin V assays were performed to examine whether Bex induces apoptosis of cancer cells. MDA-MB-231 or DU-145 cells were treated with $100 \mu \mathrm{g} / \mathrm{ml}$ Bex for $24 \mathrm{~h}$, followed by Annexin V-FITC and 7-AAD. Flow cytometry data indicated that Bex induced apoptosis of the two types of cancer cell (Fig. 2A). Consistently, Bex induced PARP cleavage and caspase activation in the MDA-MB-231 cells (Fig. 2B; data for DU-145 not shown). Thus, the current data indicates that Bex causes apoptosis of cancer cells.

Bex reduces the level of intracellular ROS. To examine whether Bex affects the production of intracellular ROS, MDA-MB-231 and DU-145 cells were treated with $100 \mu \mathrm{g} / \mathrm{ml}$ Bex for $1 \mathrm{~h}$, and the intracellular ROS level was measured by detecting H2DCF-DA fluorescence using flow cytometry. Bex increased the intracellular ROS level in MDA-MB-231 breast and DU-145 prostate cancer cells (Fig. 3).

Bex-mediated increase of intracellular ROS level is critical for apoptosis. Whether Bex-induced apoptosis required 
an increase of intracellular ROS level was subsequently examined. Bex-induced apoptosis was blocked in cells treated with NAC (Fig. 4). The data indicate that Bex-induced ROS accumulation is important for apoptosis.

\section{Discussion}

Bex has long been incorporated into diets for disease prevention. However, to the best of our knowledge, its effects in cancer are yet to be investigated. In the present study, Bex caused apoptosis of breast and prostate cancer cells by increasing the intracellular ROS level. The present data indicate that cancer could be, in part, treated using natural products in food. Bex is widely used in food. Therefore, the present study demonstrates that foods containing Bex may be useful for cancer treatment during therapeutic interventions.

A recent study demonstrated that Bex induced apoptosis of leukemia and lymphoma cell lines (30). While not shown in the present study, the data demonstrated no apoptotic effect of Bex in Jurkat $\mathrm{T}$ cells (data not shown). It is possible that the experimental conditions, such as the extraction method and concentration, may have influenced the controversial results. In the present study, Bex induced apoptotic cell death of highly metastatic MDA-MB-231 breast cancer cells and DU-145 prostate cancer cells. Thus, the anti-cancer effect of Bex is not limited to blood cancer. This is consistent with results obtained using Bex-treated B16 melanoma cells or HepG2 hepatoma cells $(31,32)$. Bex is one of the ingredients in cereal and the anti-cancer effect of peptides from cereal has previously been demonstrated (33). Furthermore, meta-analyses indicated that cereal reduces cancer risk $(34,35)$. Thus, the present study provides evidence that dietary components are beneficial for cancer prevention and treatment.

In conclusion, Bex induction of ROS was crucial for apoptotic cell death. While the chemical components to produce ROS and induce apoptotic cell death in those breast and prostate cancer cells require further investigation, this is the first study, to the best of our knowledge, that shows the role of Bex in cancer cell death.

\section{Acknowledgements}

The present study was supported by the Korean National University of Transportation 2016.

\section{References}

1. de Martel C, Ferlay J, Franceschi S, Vignat J, Bray F, Forman D and Plummer M: Global burden of cancers attributable to infections in 2008: A review and synthetic analysis. Lancet Oncol 13: 607-615, 2012.

2. McGuire S: World Cancer Report 2014. Geneva, Switzerland: World Health Organization, International Agency for Research on Cancer, WHO Press, 2015. Adv Nutr 7: 418-419, 2016.

3. Hare JI, Lammers T, Ashford MB, Puri S, Storm G and Barry ST: Challenges and strategies in anti-cancer nanomedicine de velopment: An industry perspective. Adv Drug Deliv Rev 1: 25-38, 2017.

4. Dawidczyk CM, Kim C, Park JH, Russell LM, Lee KH, Pomper MG and Searson PC: State-of-the-art in design rules for drug delivery platforms: Lessons learned from FDA-approved nanomedicines. J Control Release 187: 133-144, 2014.

5. Bellou S, Pentheroudakis G, Murphy C and Fotsis T: Anti-angiogenesis in cancer therapy: Hercules and hydra. Cancer Lett 338: 219-228, 2013.
6. Ali I, Wani WA, Saleem K and Haque A: Platinum compounds: A hope for future cancer chemotherapy. Anticancer Agents Med Chem 13: 296-306, 2013.

7. Fauzee NJ: Taxanes: Promising anti-cancer drugs. Asian Pac J Cancer Prev 12: 837-851, 2011.

8. Vera-Badillo FE, Al-Mubarak M, Templeton AJ and Amir E: Benefit and harms of new anti-cancer drugs. Curr Oncol Rep 15: 270-275, 2013.

9. Ghorbani A: Clinical and experimental studies on polyherbal formulations for diabetes: Current status and future prospective. J Integr Med 12: 336-345, 2014.

10. Jiang M, Yang J, Zhang C, Liu B, Chan K, Cao H and Lu A: Clinical studies with traditional Chinese medicine in the past decade and future research and development. Planta Med 76: 2048-2064, 2010.

11. Ilyas U, Katare DP, Aeri V and Naseef PP: A review on hepatoprotective and immunomodulatory herbal plants. Pharmacogn Rev 10: 66-70, 2016.

12. Bahmani M, Shirzad H, Shahinfard N, Sheivandi L and Rafieian-Kopaei M: Cancer phytotherapy: Recent views on the role of antioxidant and angiogenesis activities. J Evid Based Complementary Altern Med 2156587215625157, 2016.

13. Xu H, Zhao X, Liu X, Xu P, Zhang K and Lin X: Antitumor effects of traditional Chinese medicine targeting the cellular apoptotic pathway. Drug Des Devel Ther 9: 2735-2744, 2015.

14. Ichikawa H, Nakamura Y, Kashiwada Y and Aggarwal BB: Anticancer drugs designed by mother nature: Ancient drugs but modern targets. Curr Pharm Des 13: 3400-3416, 2007.

15. Poonthananiwatkul B, Howard RL, Williamson EM and Lim RH: Cancer patients taking herbal medicines: A review of clinical purposes, associated factors, and perceptions of benefit or harm. J Ethnopharmacol 175: 58-66, 2015.

16. Lee JW, Lee WB, Kim W, Min BI, Lee $\mathrm{H}$ and Cho SH: Traditional herbal medicine for cancer pain: A systematic review and meta-analysis. Complement Ther Med 23: 265-274, 2015.

17. Leggett S, Koczwara B and Miller M: The impact of complementary and alternative medicines on cancer symptoms, treatment side effects, quality of life, and survival in women with breast cancer - a systematic review. Nutr Cancer 67: 373-391, 2015.

18. Bao Y, Kong X, Yang L, Liu R, Shi Z, Li W, Hua B, Hou W: Complementary and alternative medicine for cancer pain: An overview of systematic reviews. eCAM 2014: 170396, 2014. https://doi.org/10.1155/2014/170396.

19. Wang CY, Bai XY and Wang CH: Traditional Chinese medicine: A treasured natural resource of anticancer drug research and development. Am J Chin Med 42: 543-559, 2014.

20. Ohnishi S and Takeda H: Herbal medicines for the treatment of cancer chemotherapy-induced side effects. Front Pharmacol 6: 14, 2015.

21. Park B, Jun JH, Jung J, You S and Lee MS: Herbal medicines for cancer cachexia: Protocol for a systematic review. BMJ Open 4: e005016, 2014.

22. Lahouar L, El-Bok S and Achour L: Therapeutic potential of young green barley leaves in prevention and treatment of chronic diseases: An overview. Am J Chin Med 43: 1311-1329, 2015.

23. Miyazaki Y, Tokunaga Y, Takagaki K, Tsusaki S, Tachibana H and Yamada K: Effect of dietary cabbage fermentation extract and young barley leaf powder on immune function of Sprague-Dawley rats. J Nutr Sci Vitaminol (Tokyo) 47: 253-257, 2001.

24. Cremer L, Herold A, Avram D and Szegli G: Inhibitory capacity of some fractions isolated from a green barley extract upon TNF alpha production by the cells of the THP-1 human monocytes line. Roum Arch Microbiol Immunol 55: 285-294, 1996.

25. Cremer L, Herold A, Avram D and Szegli G: A purified green barley extract with modulatory properties upon TNF alpha and ROS released by human specialised cells isolated from RA patients. Roum Arch Microbiol Immunol 57: 231-242, 1998.

26. Iguchi T, Kawata A, Watanabe T, Mazumder TK and Tanabe S: Fermented barley extract suppresses the development of atopic dermatitis-like skin lesions in NC/Nga mice, probably by inhibiting inflammatory cytokines. Biosci Biotechnol Biochem 73: 489-493, 2009.

27. Choi KC, Hwang JM, Bang SJ, Son YO, Kim BT, Kim DH, Lee SA, Chae M, Kim DH and Lee JC: Methanol extract of the aerial parts of barley (Hordeum vulgare) suppresses lipopolysaccharide-induced inflammatory responses in vitro and in vivo. Pharm Biol 51: 1066-1076, 2013. 
28. Hong $\mathrm{H}$ and Jai Maeng W: Effects of malted barley extract and banaba extract on blood glucose levels in genetically diabetic mice. J Med Food 7: 487-490, 2004.

29. Yu YM, Chang WC, Chang CT, Hsieh CL and Tsai CE: Effects of young barley leaf extract and antioxidative vitamins on LDL oxidation and free radical scavenging activities in type 2 diabetes. Diabetes Metab 28: 107-114, 2002.

30. Robles-EscajedaE,Lerma D,Nyakeriga AM, Ross JA, Kirken RA, Aguilera RJ and Varela-Ramirez A: Searching in mother nature for anti-cancer activity: Anti-proliferative and pro-apoptotic effect elicited by green barley on leukemia/lymphoma cells. PLoS One 8: e73508, 2013.

31. Ghavami L, Goliaei B, Taghizadeh B and Nikoofar A: Effects of barley $\beta$-glucan on radiation damage in the human hepatoma cell line HepG2. Mutat Res Genet Toxicol Environ Mutagen 775: $1-6,2014$.

32. Meng TX, Irino N and Kondo R: Melanin biosynthesis inhibitory activity of a compound isolated from young green barley (Hordeum vulgare L.) in B16 melanoma cells. J Nat Med 69: 427-431, 2015 .
33. Ortiz-Martinez M, Winkler R and García-Lara S: Preventive and therapeutic potential of peptides from cereals against cancer. J Proteomics 111: 165-183, 2014.

34. Lei Q, Zheng H, Bi J, Wang X, Jiang T, Gao X, Tian F, Xu M, Wu C, Zhang L, et al: Whole grain intake reduces pancreatic cancer risk: A meta-analysis of observational studies. Medicine (Baltimore) 95: e2747, 2016.

35. Aune D, Keum N, Giovannucci E, Fadnes LT, Boffetta P, Greenwood DC, Tonstad S, Vatten LJ, Riboli E and Norat T: Whole grain consumption and risk of cardiovascular disease, cancer, and all cause and cause specific mortality: Systematic review and dose-response meta-analysis of prospective studies. BMJ 353: i2716, 2016 